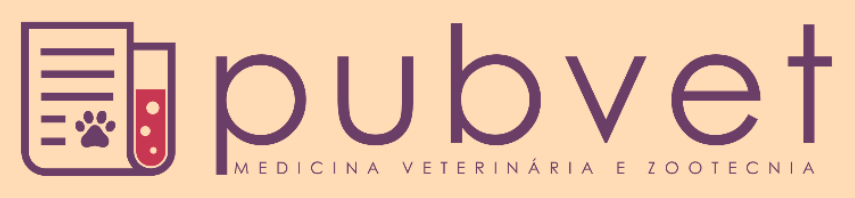

ISSN $1982-1263$

https://doi.org/10.31533/pubvet.v14n1a481.1-5

\title{
Bem-estar e suas perspectivas na produção animal
}

\author{
Hierro Hassler Freitas Azevedo ${ }^{1 *} \bullet$, Aline Pacheco ${ }^{2} \bullet$, Adcleia Pereira Pires ${ }^{3}$, Jonival Santos \\ Nascimento Mendonça Neto ${ }^{\circ}{ }^{\circ}$, Daniela Ariana Gama Pena ${ }^{5}$, Andria Tavares Galvão ${ }^{6}{ }^{\circ}$, Emely \\ Daniela Mezzalira Ferrari ${ }^{\circ} \bullet$, Beatriz Vilas Boas Ferreira de Almeida ${ }^{\circ} \bullet$, Thayanne Vanessa \\ Lais de Oliveira Batista ${ }^{5}$, Ceiça Freitas Araújo ${ }^{5} \bullet$, Wanessa Laís de Oliveira Batista ${ }^{5}$
}

${ }^{1}$ Bacharel em Ciências Agrárias - Produção Animal na Universidade Federal do Oeste do Pará. Santarém - PA.

${ }^{2}$ Professora da Universidade Federal do Oeste do Pará do curso de zootecnia. Santarém - PA.

${ }^{3}$ Zootecnista - PA.

${ }^{4}$ Graduando(a) em Medicina Veterinária da Universidade da Amazônia. Santarém - PA.

${ }^{5}$ Graduanda em Zootecnia na Universidade Federal do Oeste do Pará. Santarém - PA.

*Autor para correspondência, E-mail: hierro.azvdo@gmail.com

Resumo. O bem-estar animal apresenta premissas da preocupação com o animal de produção, pois o mesmo possui direito de expressar seu comportamento natural e ter acesso as suas necessidades fisiológicas, psicológicas e comportamentais. Estudos apontam aumento na produção e reprodução quando o animal tem acesso às cinco liberdades, pois o animal com uma boa genética pode expressar todo o seu potencial produtivo ou reprodutivo, de acordo com suas aptidões, além de melhorar a qualidade do produto final. Portanto, o objetivo desta revisão é apontar quais são as perspectivas e influência do bemestar animal na produção, sua interferência na produtividade e economia. Dentro destas perspectivas de produção, o bem-estar animal proporciona maior lucratividade, pois surge o perfil de consumidor ético, que deseja comprar alimentos de origem animal que estiveram sob condições de bem-estar durante seu ciclo de vida até o abate, onde o animal não passou por sofrimentos e pode expressar seu potencial de produção e reprodução, além de atender a exigência do mercado externo.

Palavras chave: comportamento, cinco liberdades, economia, ética, estresse

\section{Well-welfare and it's prospect in animal production}

\begin{abstract}
Animal welfare presents premises of concern with the production animal, since it has the right to express its natural behavior and to have access to its physiological, psychological and behavioral needs. Studies show an increase in production and reproduction when the animal has access to the five freedoms, since the animal with a good genetics can express all its productive or reproductive potential, according to its abilities, besides improving the quality of the final product. Therefore, the purpose of this review is to raise the prospects and influence of animal welfare in production, its interference in productivity and economy. Within these production perspectives, animal welfare provides greater profitability, as the profile of an ethical consumer arises, who wishes to buy food of animal origin that has been under welfare conditions during its life cycle until slaughter, where the animal does not suffered from suffering and can express its production and reproduction potential, in addition to meeting the requirements of the foreign market.
\end{abstract}

Keywords: behavior, five freedoms, economy, ethics, stress 


\title{
Bienestar y sus perspectivas en la producción animal
}

\begin{abstract}
Resumen. El bienestar animal tiene suposiciones de preocupación por el animal de producción, porque tiene derecho a expresar su comportamiento natural y tener acceso a sus necesidades fisiológicas, psicológicas y conductuales. Los estudios apuntan un aumento en la producción y reproducción cuando el animal tiene acceso a las cinco libertades, ya que el animal con una buena genética puede expresar todo su potencial productivo o reproductivo, según sus habilidades, además de mejorar la calidad del producto final. Por lo tanto, el objetivo de esta revisión es elevar cuáles son las perspectivas y la influencia del bienestar animal en la producción, su interferencia en la productividad y la economía. Dentro de estas perspectivas de producción, el bienestar animal propone una mayor rentabilidad, ya que surge el perfil ético de consumo, que quiere comprar alimentos de origen animal que han estado en condiciones de bienestar durante su ciclo de vida hasta el sacrificio, donde el animal no ha experimentado sufrimiento y puede expresar su potencial de producción y reproducción, además de satisfacer la demanda del mercado exterior.
\end{abstract}

Palabras clave: comportamiento, cinco libertades, economía, ética, estrés

\section{Introdução}

A definição do bem-estar animal não se restringe somente aos objetivos de produtividade como apontados por Broom (2006); pode ser definido como o estado de harmonia do animal com o meio em que vive. Os princípios de bem-estar de animais de produção (aves, suínos, ovinos, caprinos, bubalinos, bovinos, entre outros).

A frase "bem-estar animal" refere-se ao bem-estar físico e ao mental do animal, envolvendo as necessidades e estados de bem-estar dos mesmos, o indício de problemas que geram sofrimento e dor, a manifestação da necessidade de mudanças no manejo que assumam compromisso com o respeito e a ética em relação a outros seres vivos. A interrelação do convívio aplicado às relações dos seres humanos com os animais e, logo, perceber, avaliar e garantir as condições para satisfação dos animais é essencial para o sucesso da cadeia produtiva (Broom \& Molento, 2004; Koknaroglu \& Akunal, 2013). O bem-estar animal se refere ao manejo e a aplicação de boas práticas relacionada entre humanos e animais, a racionalidade na criação aos animais domésticos quer seja de produção ou não, mas que haja respeito aos direitos referentes às cinco liberdades previstas por lei, descritos no decorrer do trabalho. Dentro desta perspectiva, as tecnologias são aplicadas com orientações científicas que venham propiciar conforto em relação às instalações e tratadores (Broom, 1986).

A importância do bem-estar animal é de fato um ponto crucial para a economia e pode ter relevante impacto dentro das politicas de consumo interno e externo, pois atualmente buscam-se alimentos com qualidade e segurança alimentar, e isso está muito relacionado ao consumo com princípios éticos (Fraser, 2009; Gregory \& Grandin, 2007; Hötzel \& Machado Filho, 2004). Portanto, bem-estar animal deixa de ser uma preocupação interna, pois o mercado de exportação, a Europa tem como exigência na compra de produtos de origem animal a certificação de bem-estar de animais de produção, seja qual for o país de origem (Campo et al., 2014; Dawkins, 2017; Gregory \& Grandin, 2007).

Desta forma, o bem-estar animal, está envolvido por um conjunto que permeiam a boa nutrição, boa saúde, bom manejo, instalações adequadas e expressão de particularidades comportamentais de cada espécie, que são diretamente relacionados com características que interessam ao setor de produção animal, destacando-se: a expressão genética e característica da espécie, crescimento, ganho de peso, desempenho na reprodução, qualidade da carcaça e carne, inerte a doenças ou resistentes e segurança dos trabalhadores e animais.

\section{Bem-estar animal}

A ciência do bem-estar animal, na visão de Broom \& Molento (2004), revela que bem-estar animal (BEA) vai além dos sentimentos subjetivos dos animais, mas consideram-se também suas preferências, 
podendo usar como subsídio na oferta de melhorias ao meio ofertado e condições de adaptabilidade do animal, como reflexo, do seu bem-estar.

No ano de 2010, Grandin \& Johnson (2010), na obra $O$ bem-estar dos animais, apresentam a importância do ambiente e as condições ofertadas aos animais, para que estes possam demonstrar suas emoções positivas e não as negativas sob condições de necessidade (Grandin \& Johnson, 2010). Nesse sentido, é importante evitar o estresse ao animal, para que ele não apresente comportamento análogo, como raiva, medo e pânico, mas sim, ambiente e condições proximais a espécie e suas necessidades.

Em 1965, no primeiro relatório do Comitê Brambell foram pensadas as "Cinco Liberdades" criadas e difundidas pelo Farm Animal Welfare Comitee (FAWC, 2009): os animais devem estar livres de desconforto; livres de dor; de maus tratos e doenças; livres para expressar seu comportamento natural e livre de medo e de tristeza. Quando pensa em bem-estar, é necessário relacionar o animal, ambiente, as condições do ambiente e o manejo, a relação homem e animal (Broom, 1991; Broom, 2006; Broom \& Fraser, 2010).

Pontuando as "Cinco Liberdades" apresentadas acima:

1. Livre de fome e de sede - acesso à água fresca de qualidade e a uma dieta adequada às condições fisiológicas dos animais.

2. Livre de desconforto - de um ambiente adequado que inclua um abrigo com uma zona de descanso confortável.

3. Livre de dor, ferimentos e doença - prevenção de doenças, diagnóstico rápido e tratamentos adequados.

4. Liberdade de expressar comportamento normal - fornecimento de espaço adequado, instalações adequadas e a companhia de animais da mesma espécie.

5. Livre de estresse, medo e ansiedade - assegurando condições e manejo que evitem sofrimento mental.

Todavia, os produtores da era moderna buscam se encaixar nas premissas das "Cinco Liberdades" (base do bem-estar), que visa o respeito ao bem-estar animal, hoje legitimado pelo Ministério da Agricultura, Abastecimento e Pecuária, bem como exigência dos países europeus.

\section{Bem-estar animal versus sistemas de produção}

Para Losada-Espinosa et al. (2018) o bem-estar animal perpassa a economia mundial, ou as novas tendências do mercado sustentável e ou verde. Todavia, uma necessidade científica, se faz necessário para o crescimento e desenvolvimento da pecuária e suas atividades. Neste contexto, a atividade agropecuária trabalha em função da produção e economia, num tripé de criação, produção e reprodução (Porcher, 2004). Diante disso, a criação racional de animais em confinamento ou semi-confinamento, denominadas de criação intensiva, semi-intensiva ou extensiva desencadeia discussões cientificas voltadas para produção, quantidade, qualidade e bem-estar (Dawkins, 2017; Waterhouse, 1996).

As referências no Brasil sobre bem-estar animal são os relatórios do Comitê Brambell, a teoria e as inovações tecnológicas de Temple Grandin (Grandin \& Johnson, 2010) e os conceitos e parâmetros estabelecidos por Donald Broom (Broom, 1991). Depois de avaliações de animais de produção, em criações em sistema intensivo, com diagnósticos que apresentam condições não aceitáveis, critérios de bem-estar foram propostos e aplicados com o propósito de minimizar a dor e o sofrimento dos animais. Aos produtores é evidenciada a lucratividade da implantação das práticas de bem-estar animal, justificando as preocupações de ordem sanitária, que buscam garantir carne e carcaças de qualidade (Gregory \& Grandin, 2007). É a premissa do boletim informativo sobre bem-estar animal no Brasil distribuído pelo Ministério da Agricultura Pecuária e Abastecimento (MAPA, 2008).

O Ministério da Agricultura, Pecuária e Abastecimento (MAPA) publicou a Instrução Normativa ${ }^{\circ}$ 56 (IN 56 - de 06/11/2008). A Norma estabelece procedimentos gerais de práticas de bem-estar para animais de produção.

Para a garantia do bem-estar animal, a Instrução Normativa $\mathrm{N}^{\circ} 56$ estabelece que devam ser observados os seguintes princípios:

- Proceder ao manejo cuidadoso e responsável nas várias etapas da vida do animal, desde o 
nascimento, criação e transporte;

- Possuir conhecimentos básicos de comportamento animal a fim de proceder ao adequado manejo;

- Proporcionar dieta satisfatória, apropriada e segura, adequada às diferentes fases da vida do animal:

- Assegurar que as instalações sejam projetadas apropriadamente aos sistemas de produção das diferentes espécies de forma a garantir a proteção, a possibilidade de descanso e o bem-estar animal;

- Manejar e transportar os animais de forma adequada para reduzir o estresse e evitar contusões e o sofrimento desnecessário;

- Manter o ambiente de criação em condições higiênicas (MAPA, 2008).

A preocupação com o ambiente não natural do animal surge devido ao comportamento que o mesmo pode apresentar por necessidades fisiológicas e biológicas. Desta forma, O enriquecimento ambiental é o meio proposto para aqueles animais que não vivem no ambiente natural, ou próprio da espécie, como chiqueiros, currais e galinheiros. Tais ambientes, quando não comportam o número de indivíduos por área e contém superlotação, os indivíduos podem manifestar comportamentos estereotípicos, definidos por Grandin como "comportamentos anormais repetitivos, invariáveis [...] e aparentemente sem motivo" (Grandin \& Johnson, 2010), como lamber as cercas dos currais, mastigar sem haver alimentos na boca, girar em torno do próprio corpo. Tais estereotipias manifestam condições em que estes animais não estão em bem-estar. Desta maneira, certas alterações da fisiologia e/ou do comportamento de um animal podem ser indicativas de comprometimento de seu bem-estar. As alterações podem ser medidas de forma objetiva e constituem uma importante estrutura de avaliação do bem-estar animal, pelos níveis séricos de cortisol e porcentual de tempo gasto em comportamentos estereotípicos, são exemplos de parâmetros medidos (Broom \& Fraser, 2010; Broom \& Molento, 2004).

O planejamento das instalações é de suma importância para a promoção do bem-estar, como espaço apropriado; área de descanso seca e ventilada; sombreamento; espaço de cocho apropriado para alimento por indivíduos (e reduzir competição); grupos homogêneos e ambientes saudáveis e agradáveis, além da área de fuga (Araújo, 2001; Curi et al., 2016). As instalações na pecuária devem dispor de dados meteorológicos da área. Na região amazônica de clima tropical, as coberturas devem ser orientadas no sentido leste-oeste, para que no verão haja menor ocorrência da luz solar e maior insolação no inverno, o espaço deve apresentar áreas amplas, de fácil acesso, boa drenagem e ventilação. Estas devem ser suficientes para alojar o número de animais existentes na propriedade, oferecendo condições de conforto físico e térmico quando alimentados, ou em qualquer atividade de interesse do produtor e seus fins de manejo.

\section{Considerações finais}

Os animais de produção apresentam necessidades distintas, tais como: ambiente, ambiência, instalações, manejo, nutrição, entre outros meios que venham a proporcionar bem-estar para estes, desde a fase de cria, transporte e abate. Ressaltando a necessidade de oferta de conforto térmico, devido à variação climática e umidade de cada região, considerando a espécie animal, genética e seu desempenho de produção. Dentro destas perspectivas de produção, o bem-estar animal proporcina maior lucratividade, pois surge o perfil de consumidor ético, que deseja comprar alimentos de origem animal que estiveram em condições de bem-estar durante seu ciclo de vida até $\mathrm{o}$ abate, onde o animal não passou por sofrimentos e pode expressar seu potencial de produção e reprodução, além de atender a exigência do mercado externo.

\section{Referências bibliográficas}

Araújo, A. P. (2001). Estudo comparativo de diferentes sistemas de instalações para produção de leite tipo B, com ênfase nos índices de conforto térmico e na caracterização econômica. Master of Science, Universidade de São Paulo, São Paulo.

Broom, D. M. (1986). Indicators of poor welfare. British Veterinary Journal, 142(6):524-526.

Broom, D. M. (1991). Animal welfare: concepts and measurement. Journal of Animal Science, 69(10):4167-4175. 
Broom, D. M. (2006). Behaviour and welfare in relation to pathology. Applied Animal Behaviour Science, 97(1):73-83. doi: http://dx.doi.org/10.1016/j.applanim.2005.11.019

Broom, D. M. \& Fraser, A. F. (2010). Comportamento e bem-estar de animais domésticos. São Paulo, Brasil: Editora Manole.

Broom, D. M. \& Molento, C. F. M. (2004). Animal welfare: concept and related issues-review. Archives of Veterinary Science, 9(2):1-11.

Campo, M. M., Brito, G., Montossi, F., Soares de Lima, J. \& San Julián, R. (2014). Animal welfare and meat quality: The perspective of Uruguay, a "small" exporter country. Meat science, 98470-476.

Curi, T. M. R. C., Vercellino, R. D. A., Massari, J. M., Souza, Z. M. \& Moura, D. J. (2016). Geoestatística para avaliação do controle ambiental do sistema de ventilação em instalações comerciais para frangos de corte. Engenharia Agrícola, 34(6):1062-1074.

Dawkins, M. S. (2017). Animal welfare and efficient farming: is conflict inevitable? Animal Production Science, 57(2):201-208.

FAWC. (2009). Farm animal welfare in Great Britain: Past, present and future. England: Farm Animal Welfare Council.

Fraser, D. (2009). Animal behaviour, animal welfare and the scientific study of affect. Applied Animal Behaviour Science, 118(3-4):108-117. doi: http://dx.doi.org/10.1016/j.applanim.2009.02.020

Grandin, T. \& Johnson, C. (2010). O bem-estar dos animais: proposta de uma vida melhor para todos os bichos. Rio de Janeiro, Brasil: Rocco.

Gregory, N. G. \& Grandin, T. (2007). Animal welfare and the meat market. Cambridge: CABI.

Hötzel, M. J. \& Machado Filho, L. C. P. (2004). Bem-estar animal na agricultura do século XXI. Revista de Etologia, 6(1):3-15.

Koknaroglu, H. \& Akunal, T. (2013). Animal welfare: An animal science approach. Meat Science, 95(4):821-827. doi: http://dx.doi.org/10.1016/j.meatsci.2013.04.030

Losada-Espinosa, N., Villarroel, M., María, G. A. \& Miranda-de la Lama, G. C. (2018). Pre-slaughter cattle welfare indicators for use in commercial abattoirs with voluntary monitoring systems: A systematic review. Meat Science, 13834-48. doi: https://doi.org/10.1016/j.meatsci.2017.12.004

MAPA, 2008. Bem estar animal, o Brasil se importa. Disponível em: http://www.agricultura.gov.br/pls/portal/docs/PAGE/MAPA/SERVICOS/BEM_ESTAR_ANIMAL / BEM\%20ESTAR\%20ANIMAL_0.PDF , acesso 29 de Março de 2018.

Porcher, J. (2004). "Você liga demais para os sentimentos "'Bem-estar animal', repressão da afetividade, sofrimento dos pecuaristas". Produção, 14(3):35-44.

Waterhouse, A. (1996). Animal welfare and sustainability of production under extensive conditions-a European perspective. Applied Animal Behaviour Science, 49(1):29-40.

Recebido: 1 de junho, 2019.

Aprovado: 14 de outubro, 2019.

Publicado: 29 de fevereiro, 2020.

Licenciamento: Este artigo é publicado na modalidade Acesso Aberto sob a licença Creative Commons Atribuição 4.0 (CC-BY 4.0), a qual permite uso irrestrito, distribuição, reprodução em qualquer meio, desde que o autor e a fonte sejam devidamente creditados. 